\title{
Culture Impact on the Term Geo-ethics in Egypt
}

\author{
Kholoud Abdel Maksoud ${ }^{1}$, Nada Abdel-Hak ${ }^{2}$ and Mohamed Galal ${ }^{1}$ \\ 1. Institute of African Research and Studies, Cairo University, Cairo 12613, Egypt \\ 2. Faculty of science, Cairo University, Cairo 12613, Egypt
}

\begin{abstract}
Geoethics is a new term that could be unknown in the Arab world, where its translation in Arabic language poses some problems, especially in Egypt. Spreading this term and its importance to professionals and population is not an easy task. These cultural and awareness problems force us to understand and act to solve them. In this paper the authors have studied two samples of people with different education levels: the first one is formed by young geoscientists and the other one is formed by young people coming from different disciplines. The two groups of people have been initially the subject of a survey (by monitoring a base level) about the knowing of geoethics. In a second phase, they have been the subject of another survey after giving them some lectures and workshops on geoethics. The goal of the research was to find out how people accept the term "geoethics" and its application and how we can spread it effectively into communities in different ways. In Egypt there are some cultural problems that could affect on spreading of any new concept. These problems could be overcome by some scientific, social and culture actionable recommendations, and these recommendations could be applied in both Arab and African countries with few modifications.
\end{abstract}

Key words: Geo-ethics, learning, Egypt, culture impact.

\section{Introduction}

A new relationship was established in 40s between humans and the natural environment by Aldo Leopold to identify between men and land [1]. While in 60s the developments of environmental awareness resulted in the birth of several environmental movements that acted and continue to act primarily to safeguard the biosphere, although with important differences in their approaches to saving the Earth. Environmentalism has gradually become an articulated phenomenon, one which proposes different strategies towards protecting the nature and the biodiversity as a result of more than one vision [2].

Ref. [3] stated that "Conservation Ethics" considers that "nature" must be preserved in a relationship of subordination to the needs of mankind. Because natural resources are functional to human life, society must exploit them in a sustainable way, through actions that allow their rational and prudent use, all the while being aware of their limits and potential for exhaustibility.

Corresponding author: Kholoud Abdel Maksoud, Ph.D., Dr., research field: economic geology.
Environmental ethics oscillates between extreme positions, from anthropocentrism [4] to eco-centrism $[5,6]$. The former promotes the vision of humans as separate from nature, while the latter considers humans as an integral part of nature.

Geoethics rediscovers, expands, and enhances the cultural dimension of geoscience knowledge [7-9] as a basic element of a holistic vision that goes beyond the dualism between humans and nature. Geoethics emphasizes the ethical criterion of responsible human action towards the Earth [9], not only in its biotic components (biodiversity) but also in the abiotic (geodiversity).

The geologist Antonio Stoppani (1824-1891) [10] introduced the concept of the "Anthropozoic Era”. He identified humans as a new "geological force" and thus as an integral and essential part of nature. As an early populariser of geological knowledge, Stoppani thus became one of the pioneers of geoethics.

Geoethics recognizes the contingency of human evolution on the planet $[11,12]$, identifies Homo sapiens as a geological force acting on the geological and biological environments, and assigns to humans an 
ethical responsibility that arises from the consciousness of being a modifier of Earth systems.

Near the end of the last century the more modern concept of the Anthropocene finally crystallized [13]. An intense scientific debate about this concept ensued. Because geology adheres to temporal and stratigraphic limits $[14,15]$, geoethics is a discipline required in order to understand the inevitable consequences (positive and negative) of human progress, especially when we consider the enormous amount of energy and natural resources used for economic development and the wide environmental spaces occupied and modified by human beings. The incredible increase in population and the legitimate aspirations of every individual to 5 improve his or her own material conditions can find in geoethics a frame of reference for values rooted in geological thinking, which has the peculiar characteristic of being able to analyze space and time in a perspective that goes beyond the human experience but that accepts the presence of people on the planet as a natural consequence of the unpredictability of natural evolution [11, 12].

Geoethics provides a framework for any human action on the geosphere. The responsibility that derives from this framework is the basis of the semantic meaning of the word "ethics" [16]. Therefore, the word "geoethics", as used starting from the early 1990s [17, 18], signifies the duty of mankind to behave responsibly and become the natural consciousness of the planet. To place humans at the center of the discussion on geoethics does not represent a new form of anthropocentrism but rather stresses that only by accepting their responsibility initially towards themselves, can humans become fully aware of their role as an active "geological" force. Then changes in the dynamics of Earth systems can be made, when necessary, through responsible behaviors and proper practices towards geodiversity and biodiversity [19]. So, geo-ethics is the interaction of humans with the geosphere, from which we cannot be separated while dealing with earth in all fields.

Geo-ethics is not known in Egypt since two years, also it was considered as a mysterious term for geoscientists. In 2015 the IAPG established an international branch in Egypt, so the coordinators try to make an international chapter in Egypt by inviting students and academic stuff to share in this activity, but it turned out that no one knows what is meant by Geo-ethics even professors in Geo-departments! From this point it was a must to know first what is meant by this term to people and by what means we can spread the mission of the IAPG.

The term ethics (in Arabic language) in Egypt reflects unacceptable behavior from others as if we are telling the person that your behavior is inconvenient, and this was also taken in consideration, how to translate the term in a convenient meaning to the Egyptian culture.

\section{Methods Used in Monitoring}

In the case of monitoring the acceptance of a new term with people of different backgrounds and focusing on gender as it was one of the main aims how to spread the term in the society, questioner was considered one of the most important tools before and after knowing the meaning of the term.

Three types of questioners were used in this study, for 2 different samples of peoples.

The chosen sample was taken in Cairo University only, where all universities refused the idea of making a lecture or even a workshop. The two samples were targeting specialized and unspecialized students with different ages.

Females males ratios in the two samples are: Sample I $56 \%$ females and $44 \%$ males, while in Sample II females percentage is $44 \%$ and male $56 \%$.

In Sample I two workshops were done to the post-graduate students, to discuss the meaning and application of geo-ethics in Egypt and if it could be applied or not. 


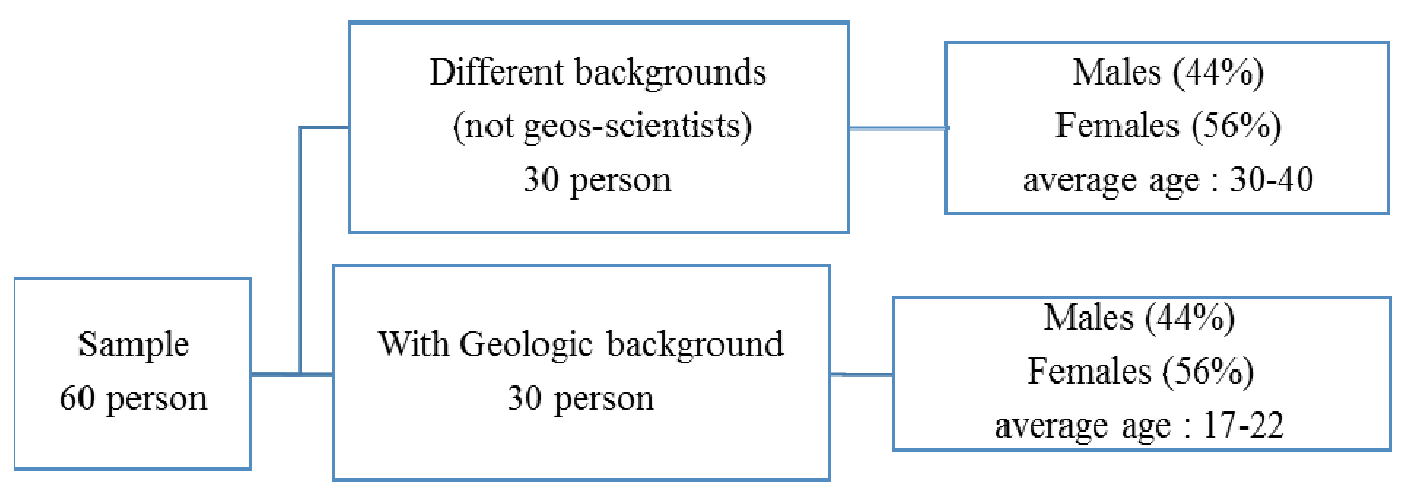

Fig.1 Shows sample classification, in number and gender.

\section{Questioner description}

Pre-questioner for Sample I

Q1. Did you hear about geo-ethics as a term before?

Q2. Would you like to know what is meant by geo-ethics?

Q3. Do you think that this term is common?

Q4. Do we have to translate this term in Arabic?

Q5. Do you find that the translation of this term in Arabic coping with our society?

Post-questioner (after workshops)

Q1. Do you find this principle is important value and we have to know it?

Q2. Do you want to know more about Geo-ethics?

Q3. Do you find that the Arabic translation of the term Geo-ethics is acceptable in our culture?

Q4. Do you find matching between the term geo-ethics and the workshop content?

Q5. Do you recommend changing the term to be more obvious?

Q6. Do you want to be part in a team working in geo-ethics?

Q7. Do you recommend establishing a promise to geo-scientists in Egypt?

Q8. Do you find this promise valueless?

Q9. Do you find that this promise should be obligatory in universities?

Q10. Do you recommend teaching Geo-ethics in the syllabus?

Sample II questioner

Q1. Do you know the term Geo-ethics?

Q2. Can you predict the meaning of this term?

\subsection{Observed Results}

After analyzing the pre- and post-questioner that the results vary between genders, where the pre-questioner shows that males are more knowledgeable than females.

Pre-questioner Sample I results (Different background)

Q1. Did you hear about geo-ethics as a term before?

Less than $20 \%$ answered yes, which is a very few percent reflecting the little knowledge of this term, $80 \%$ of this $20 \%$ are males showing that males are of good knowledge of new terms.

Q2. Do you want to know more about Geo-ethics?

More than $80 \%$ answered yes who did not know the term before, so they are willing to know and are interested in the topic, less than $20 \%$ are not willing to know and are all males reflecting more desire of females than males to know.

Q3. Do you find that the Arabic translation of the term Geo-ethics is acceptable in our culture?

Less than $40 \%$ answered yes who know the term before.

Q4. Do we have to translate this term in Arabic?

$60 \%$ answered yes, reflecting the importance of the translation and identification of the term in Arabic.

Q5. Do you find that the translation of this term in Arabic coping with our society?

Less than $40 \%$ agreed that the meaning of the term is still uncommon among the common people.

\subsection{Post-questioner (after Workshop)}

Q1. Do you find this principle is important value and 
we have to know it?

More than $90 \%$ confirmed the importance of the principal of geoethics.

Q2. Do you want to know more about Geo-ethics?

More than $70 \%$ think that geoethics is valuable.

Q3. Do you find that the Arabic translation of the term Geo-ethics is acceptable in our culture?

90\% found that the Arabic translation to this term will not be convenient in our Egyptian culture, where the term in Arabic could have some conations about moral and ethical personal behavior which make them repel the term.

Q4. Do you find matching between the term geo-ethics and the workshop content?

85\% found matching between the term and the workshop content.

Q5. Do you recommend changing the term to be more obvious?

$30 \%$ recommend changing the term to be clearer.

Q6. Do you want to be part in a team working in geo-ethics?

Less than $40 \%$ would like to be part in a team working in geoethics (this related to the uncommon use of the term in Egypt).

Q7. Do you recommend establishing a promise to geo-scientists in Egypt?

$70 \%$ recommend having a promise for geo-scientists.

Q8. After applying the geo-promise do you find it valuable and useful?

$65 \%$ found that the promise will be valuable and useful.

Q9. Do you find that this promise should be obligatory in universities?

$65 \%$ found that it has to be obligatory.

Q10. Do you recommend teaching Geo-ethics in the syllabus?

$50 \%$ found that it has to be taught in syllabus.

$20 \%$ found it should be as workshops and open lectures.

$30 \%$ found that it has to be both in syllabus and by workshops depending on the stakeholders.

\subsection{Sample II Questioner Results (Geologic Background)}

Q1. Do you know the term Geo-ethics?

$17 \%$ of the males know the meaning of the term and $0 \%$ of females know the term, which means that males still have more knowledge than females even in different backgrounds.

Q2. Can you predict the meaning of this term?

$38 \%$ of females predict the right meaning of the term without lectures and workshops, and 23\% of males predict the right meaning, this indicates that females have great sense in predicting the exact meaning of the term than males.

As shown here that the percentage is disappointing if we put in consideration the geologic background of this sample, where $17 \%$ only know the term from 30 geologists.

\section{Conclusion and Recommendations}

From the previous data, it is obvious that:

\# The term Geo-ethics is mysterious to geoscientists and public.

\# There is a severe resistant from the Academic universities towards the term and its application, the workshops mainly were focusing on the main universities in Cairo, Cairo University, Al Azhar University and Ain Shams University these three universities are the main governmental universities in Cairo, we were rejected in Al Azhar and Ain Shams universities because of the term and the idea of the workshop!

\# The Arabic translation for this term is not compatible with the Egyptian society (they can accept the English term in case of working with the concept of Geo-ethics).

\# No one suggested a new Arabic term, although they do not accept the present one (need a brainstorming not just questioner).

\# Different genders resulted in difference in 
accepting the concept and willingness to know more about it (females are more interested in knowing and dealing with the term than males, this conclusion makes us focus more on females to spread the term than males)

\subsection{Some Recommendations to Overcome the Drawbacks}

\# Organizing periodical workshops to students studying Geoscience.

\# Using the social media and the media to make the term common for public.

\# Focusing on females to increase awareness in the society.

\# Making an Arabic newsletter to be sent to academic stuff in Egyptian universities.

\# Teaching the term is an essential priority to all geologic department in Egypt and Geologic Authorities (Geologic survey).

\section{Acknowledgments}

The authors are deeply thankful to Prof. Hassan Sobhy, the Dean of the Institute of African Research and Studies in Cairo University, to allow us to do the workshop, also many thanks to Prof. Mohamed Abdelrahman, head of geologic department in Faculty of science Cairo University, to make the questioner to the students.

\section{References}

[1] Leopold, A. 1949. A Sand County Almanac. New York: Oxford University Press.

[2] Marshall, A. 1993. "Ethics and the Extraterrestrial Environment.” Journal of Applied Philosophy 10 (2): 227-36.

[3] Bobrowsky, P., Cronin, V. S., Capua, G. D., Kieffer, S. W., and Peppoloni, S. 2017. "The Emerging Field of Geoethics.” In Scientific Integrity and Ethics with Applications to the Geosciences, edited by Gundersen, L. C., Special Publication American Geophysical Union, John Wiley and Sons, Inc.

[4] Passmore, J. A. 1974. "Man's Responsibility for Nature: Ecological Problems and Western Traditions.” History of Political Economy 7 (3): 392-95. Gerald Duckworth \& Co
Ltd, London, ISBN 978-0-71-560756-5.

[5] Næss, A. 1973. "The Shallow and the Deep, Long-Range Ecology Movement.” Inquiry an Interdisciplinary Journal of Philosophy 16 (1): 95-100.

[6] Devall, B., and Sessions, G. 1985. Deep Ecology: Living as if Nature Mattered. Salt Lake City: Gibbs M. Smith. ISBN: 0-87905-247-3.

[7] Frodeman, R. 1995. "Geological Reasoning: Geology as an Interpretive and Historical Science.” Geological Society of America Bulletin 107: 960-8. doi 10.1130/0016-7606.

[8] Frodeman, R., and Baker, V. 2000. Earth Matters: The Earth Sciences, Philosophy, and the Claims of Community. Upper Saddle River: Prentice Hall, 209. ISBN: 978-0-13-011996-4.

[9] Peppoloni, S., and Di Capua, G. 2012. "Geoethics and Geological Culture: Awareness, Responsibility and Challenges.” 335-41. doi: 10.4401/ag-6099. In Geoethics and Geological Culture. Reflections from the Geoitalia Conference 2011. Annals of Geophysics (Special Issue), $55,3$.

[10] Stoppani, A. 1873. Corso di Geologia. Vol. II, G. Bernardoni e G. Brigola, Editori, Milano.

[11] Pievani, T. 2009. "The World after Charles R. Darwin: Continuity, Unity in Diversity, Contingency.” Rend. Fis. Acc. Lincei, Springer 20: 355-61.

[12] Pievani, T. 2012. "Geoethics and Philosophy of Earth Sciences: The Role of Geophysical Factors in Human Evolution.” 349-53. doi: 10.4401/ag-5579. In Geoethics and Geological Culture. Reflections from the Geoitalia Conference 2011. Annals of Geophysics (Special Issue), 55, 3.

[13] Crutzen, P. J. 2002. “Geology of Mankind.” Nature 415: 23.

[14] Lewis, S. L., and Maslin, M. A. 2015. "Defining the Anthropocene.” Nature 519: 171-80. doi 10.1038/nature14258.

[15] Zalasiewicz, J., Waters, C. N., Williams, M., Barnosky, A. D., Cearreta, A., Crutzen, P., Ellis, E., Ellis, M. A., Fairchild, I. J., Grinevald, J., Haff, P. K., Hajdas, I., Leinfelder, R., McNeill, J., Odada, E. O., Poirier, C., Richter, D., Steffen, W., Summerhayes, C., Syvitski, J. P. M., Vidas, D., Wagreich, M., Wing, S. L., Wolfe, A. P., Zhishengw, A., and Oreskes, N. 2015. "When Did the Anthropocene Begin? A Mid-twentieth Century Boundary Level Is Stratigraphically Optimal. Quaternary International.” (Available online 12 January 2015). Accessed $23 \quad$ June 2015. http://dx.doi.org/10.1016/j.quaint.2014.11.045.

[16] Peppoloni, S. 2015. “Sharing Ethical Principles through Cultural Diversity: Translations of the Montreal Statement on Research Integrity. IAPG-International Association 
for Promoting Geoethics. Accessed 10 July 2015. http://www.geoethics.org/translationsMS.html.

[17] Savolainen, K. 1992. "Education and Human Rights: New Priorities.” In Adult Education for International Understanding, Human Rights and Peace. Report of the Workshop held at UIE, Hamburg, 18-19 April 1991, UIE Reports, 11: 43-8.
[18] Cronin, V. S. 1992. "On the Seismic Activity of the Malibu Coast Fault Zone, and Other Ethical Problems in Engineering Geoscience.” Geological Society of America, Abstracts with Programs 24 (7): A284.

[19] Ellis, E. C., and Haff, P. K. 2009. "Earth Science in the Anthropocene: New Epoch, New Paradigm, New Responsibilities.” EOS Trans. 90 (49): 473. 